\title{
Focal sialadenitis in patients with ankylosing spondylitis and spondyloarthropathy: a comparison with patients with rheumatoid arthritis or mixed connective tissue disease
}

L M J Helenius, J H Hietanen, I Helenius, H Kautiainen, H Piirainen, L Paimela, M Lappalainen, R Suuronen, C Lindqvist, M Leirisalo-Repo

Department of Oral and Maxillofacial Surgery, Helsinki University Central Hospital, Helsinki, Finland

L M J Helenius

R Suuronen

C Lindqvist

Department of Medicine, Division of

Rheumatology, Helsinki University Central Hospital, Helsinki, Finland L M J Helenius $\mathrm{H}$ Piirainen

M Leirisalo-Repo

Department of Oral Pathology, University of Helsinki

J H Hietanen

Department of Surgery, Päijät-Häme Central Hospital, Lahti, Finland

I Helenius

Rheumatism

Foundation Hospital, Heinola, Finland

$\mathrm{H}$ Kautiainen

Invalid Foundation, ORTON, Helsinki

L Paimela

Department of Virology, Helsinki University Central Hospital

M Lappalainen

Correspondence to: Dr Helenius, Ohjaajantie $3 \mathrm{~A}$ 4, 00400 Helsinki, Finland lmhelini@mappihelsinki.fi

Accepted 21 November 2000

\begin{abstract}
Objectives-To investigate the occurrence of and risk factors for focal sialadenitis in patients with rheumatoid arthritis (RA), mixed connective tissue disease (MCTD), ankylosing spondylitis (AS), and spondyloarthropathy (SpA).

Methods-A total of 85 patients (25 with RA, 19 with MCTD, 19 with AS, 22 with SpA) participated in the study. Each patient filled out a questionnaire for eye and oral symptoms and for the use of medication, and was interviewed; other tests included Schirmer's test, laboratory tests, collection of unstimulated and stimulated whole saliva, and minor salivary gland biopsy. A focus score of $\geqslant 1$ was regarded as an indicator of focal sialadenitis.
\end{abstract}

Results-Focal sialadenitis was observed in $68 \%(57 / 84)$ of all patients. It affected $80 \%(20 / 25)$ of the patients with RA, $94 \%$ (17/18) of those with MCTD, $58 \%$ (11/19) of those with AS, and $41 \%(9 / 22)$ of those with SpA $\left(\chi^{2}\right.$ test, $\left.\mathbf{p}=0.0013\right)$. Salivary secretion correlated negatively with the focus scores-that is, severity of focal sialadenitis. Patients with focal sialadenitis had both decreased salivary secretion and decreased tear secretion significantly more often than did patients without $\left(\chi^{2}\right.$ test, $p=0.0074$ and $p=0.048$ respectively). Patients with positive rheumatoid factor (RF), antinuclear antibodies (ANA), or SSA or SSB antibodies had sialadenitis significantly more often than did patients with negative antibodies. In the subgroup of patients with AS or SpA, no associations were found between focal sialadenitis and the presence of these antibodies. Conclusion-In addition to patients with RA or MCTD, focal sialadenitis also affects a very high proportion of patients with AS or SpA. Focus scores are significantly higher in patients with $R A$ or MCTD than in those with AS or SpA. A significant association exists between focal sialadenitis and RF, ANA, SSA and SSB. However, in the subgroup of patients with AS or $\operatorname{SpA}$, no associations were found between focal sialadenitis and serological markers or clinical symptoms.

(Ann Rheum Dis 2001;60:744-749)
Secondary Sjögren's syndrome is a chronic inflammatory autoimmune disorder characterised by the triad of xerostomia, keratoconjunctivitis sicca, and another autoimmune disease. Sjögren's syndrome is known to occur with a variety of autoimmune diseases, such as rheumatoid arthritis (RA), ${ }^{1}$ systemic lupus erythematosus, ${ }^{2}$ and primary biliary cirrhosis. ${ }^{3}$ The classification criteria for Sjögren's syndrome vary between study groups. According to Fox et $a l^{4}{ }^{4}$ the verification should consider all three components of diagnostic relevance: focal sialadenitis in a biopsy sample of labial salivary gland, keratoconjunctivitis sicca, and, in the case of secondary Sjögren's syndrome, an associated disease also. The recent European classification criteria suggest that at least four out of six items (subjective oral and ocular symptoms, keratoconjunctivitis sicca, focal sialadenitis on biopsy, instrumental evidence of salivary gland involvement, and the presence of autoantibodies) correctly classify patients with primary Sjögren's syndrome. ${ }^{5}$ The classification of secondary Sjögren's syndrome accepts the presence of one of the two subjective symptoms with at least two objective items of glandular dysfunction. ${ }^{5}$

Focal sialadenitis in an adequate labial salivary gland specimen is an objective criterion and has been proposed to be a more disease specific feature of Sjögren's syndrome than xerostomia or any other feature of salivary disease ${ }^{6-9}$ Focal sialadenitis is known to be common in patients with mixed connective tissue disease (MCTD) or RA. ${ }^{10-12}$ However, only a few studies have investigated the occurrence of focal sialadenitis in seronegative arthritides, such as spondyloarthropathy ( $\mathrm{SpA}$ ) and ankylosing spondylitis (AS). ${ }^{13-15}$ Patients with these diseases are increasingly treated with sulfasalazine, a drug known to induce vasculitis, lupuslike disease, and antinuclear antibodies (ANA) ${ }^{16}$

The aim of this study was to investigate the occurrence of and risk factors for focal sialadenitis in patients with various rheumatic diseases (RA, MCTD, AS, or SpA), with special emphasis on such features in AS and $\mathrm{SpA}$, and to correlate focal sialadenitis with possible xerostomia or decreased tear secretion. We also studied the possible association between the use of antirheumatic drugs and prednisolone and the development of salivary gland inflammation. 
Table 1 Characteristics of the study groups

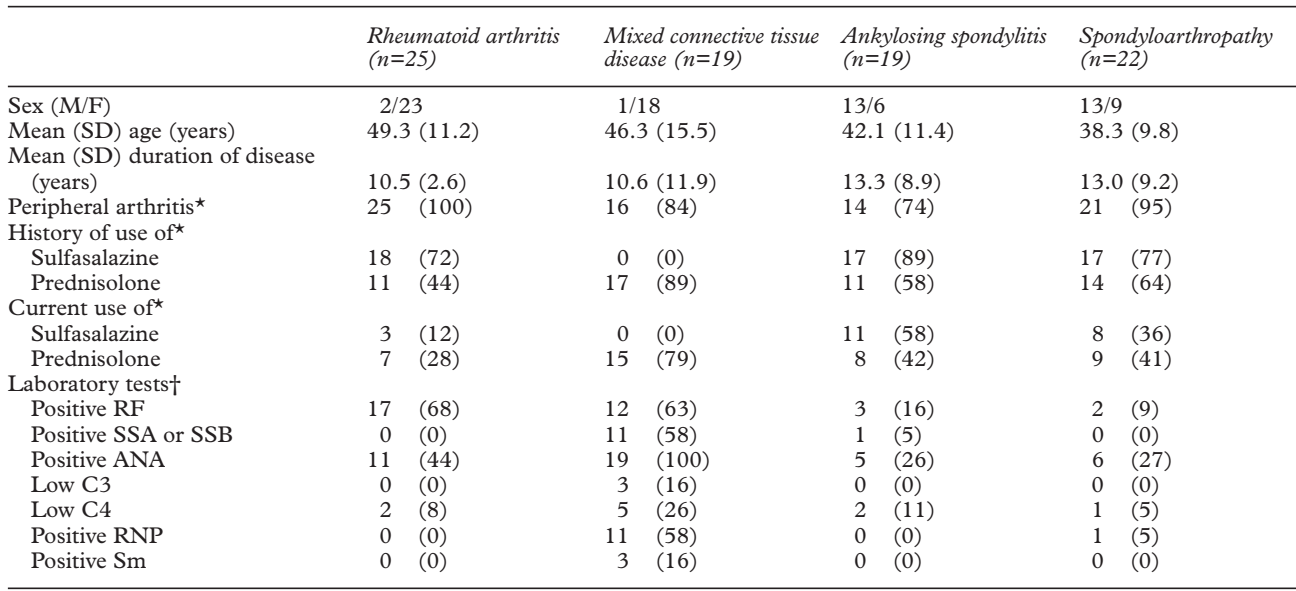

$\star$ Number of patients (\%).

†Number of patients with abnormal test result (\%).

$\mathrm{RF}=$ Rheumatoid factor; $\mathrm{ANA}=$ antinuclear antibodies; $\mathrm{RNP}=$ ribonuclear protein; $\mathrm{Sm}=\mathrm{Smith}$ antigen.

\section{Patients and methods}

PATIENTS

Eighty five patients, consisting of 25 with RA, 19 with MCTD, 19 with AS, and 22 with SpA, volunteered to participate (table 1).

All patients gave their informed written consent, and the study was approved by the ethics committee of Helsinki University Central Hospital.

All of the patients with RA fulfilled the American Rheumatism Association 1987 criteria, ${ }^{17}$ the patients with MCTD met the criteria for the diagnosis by Alarcon-Segovia, ${ }^{18}$ and the patients with AS fulfilled the modified New York criteria for definite ankylosing spondylitis. ${ }^{19}$ Other patients, with seronegative oligoarthritis or spondylitis not fulfilling the diagnostic criteria for AS, were grouped as patients with SpA and fulfilled the European Spondyloarthropathy Study Group criteria. ${ }^{20}$

\section{STUDY DESIGN}

The study was carried out from September 1996 to August 1997. All consecutive patients with MCTD, AS, or SpA treated at the Outpatient Department of Rheumatology of Meilahti Hospital, Helsinki University Central Hospital, were asked to participate in the study between September 1996 and March 1997. During the same time, patients in a continuing prospective study of early RA started in 1986-1989 were also asked to participate. The patients were asked to participate irrespective of the presence of oral or ocular symptoms. All patients asked to participate initially gave their informed consent, but later three (one with MCTD, one with AS, and one with $\mathrm{SpA}$ ) withdrew their consent.

All patients filled out a questionnaire on eye and oral symptoms according to the European Community Study Group Diagnostic Criteria for Sjögren's syndrome, ${ }^{21}$ with the following modifications. For the ocular symptoms, the question about persistent or recurrent tear gland involvement was omitted, and a question about drugs with potential to cause decreased salivary flow was added. The replies were also checked in personal interviews (conducted by
$\mathrm{L} \mathrm{M} \mathrm{J} \mathrm{H).} \mathrm{The} \mathrm{use} \mathrm{of} \mathrm{drugs} \mathrm{over} \mathrm{the} \mathrm{whole} \mathrm{dis-}$ ease period and the use of disease modifying antirheumatic drugs, other drugs for chronic diseases, and antidepressants-for example, antihypertensive, sedative, anticholinergicwere recorded. Because of the immunomodulating properties of sulfasalazine and prednisolone, we also collected data on the use of these drugs. The patients were divided into three groups: no sulfasalazine treatment at all or use for less than three months; sulfasalazine treatment for 3-11 months; sulfasalazine treatment for a year or longer. We also recorded whether or not the patient was on sulfasalazine at the time of examination. The patients were also divided into two groups according to the use of corticosteroids: those currently on corticosteroids or who had stopped the treatment less than three months ago (current use) and those without previous use of corticosteroids or if the treatment had been withdrawn more than three months ago.

\section{CLINICAL EXAMINATION}

Schirmer's test was performed using standardised tear strips (Clement Clarke, Edinburgh, UK), placed for five minutes on the conjunction at the most lateral part of the inferior lid, without previous use of anaesthetic eyedrops. The patients sat with their eyes closed, but not shut tight. After five minutes, the length of the wetted area of the strip was measured, starting from the notch corresponding to the inferior lid margin; $5 \mathrm{~mm}$ of wetted paper per five minutes was considered the lower limit of the normal value. $^{22}$

Unstimulated and stimulated saliva secretion tests were performed between 8 am and 2 $\mathrm{pm}$; the patients fasted and were not allowed to brush their teeth, rinse their mouths, or smoke for at least one hour before the procedures. During the tests, the patients were seated, inclining slightly forward. Saliva was collected in conical calibrated tubes; stimulation was induced by the patient chewing on a 2 g paraffin block. Collection time was five minutes for both the unstimulated and stimulated tests. Saliva secreted during the first 30 seconds was 
Table 2 Results of minor salivary gland biopsies, and of Schirmer's and salivary secretion tests

\begin{tabular}{|c|c|c|c|c|c|c|}
\hline & $\begin{array}{l}R A(n=25) \\
N(\%)\end{array}$ & $\begin{array}{l}M C T D(n=19) \\
N(\%)\end{array}$ & $\begin{array}{l}A S(n=19) \\
N(\%)\end{array}$ & $\begin{array}{l}S p A(n=22) \\
N(\%)\end{array}$ & $\begin{array}{l}\text { p Value between } \\
\text { groups }\end{array}$ & Post hoc testing \\
\hline Focal sialadenitis & $20(80)$ & $17(94) \ddagger$ & $11(58)$ & $9(41)$ & 0.001 & $\mathrm{RA}>\mathrm{SpA}, \mathrm{MCTD}>\mathrm{AS}, \mathrm{MCTD}>\mathrm{SpA}$ \\
\hline Decreased salivary secretion $\dagger$ & $3(12)$ & $11(61)$ & $4(22)$ & $0(0)$ & $<0.001$ & $\mathrm{RA}<\mathrm{MCTD}, \mathrm{MCTD}>\mathrm{SpA}$ \\
\hline Oral symptoms & $11(44)$ & $14(74)$ & $8(42)$ & $3(14)$ & 0.002 & $\mathrm{MCTD}>\mathrm{SpA}$ \\
\hline Decreased tear secretion $\S$ & $11(44)$ & $13(87)$ & $6(32)$ & $3(15)$ & 0.021 & MCTD $>$ SpA \\
\hline Ocular symptoms & $13(52)$ & $12(63)$ & $10(53)$ & $10(45)$ & 0.73 & \\
\hline Patients with Sjögren's syndrome & $7(28)$ & $11(73)$ & $5(26)$ & $3(15)$ & 0.021 & $\mathrm{RA}<\mathrm{MCTD}, \mathrm{MCTD}>\mathrm{AS}, \mathrm{MCTD}>\mathrm{SpA}$ \\
\hline
\end{tabular}

$\star \chi^{2}$ test.

†Either unstimulated or stimulated salivary excretion abnormal. Not studied in four patients with MCTD, two with SpA, and one with AS.

¥One minor salivary gland biopsy sample was not representative and was therefore excluded.

$\$$ Not studied in four patients with MCTD and two with SpA.

ๆFullfilling the European criteria for secondary Sjögren's syndrome. ${ }^{5}$

$\mathrm{RA}=$ Rheumatoid arthritis; $\mathrm{MCTD}=$ mixed connective tissue disease; $\mathrm{AS}=$ ankylosing spondylitis; $\mathrm{SpA}=$ spondyloarthropathy.

discarded. The lower limit of a normal value in unstimulated saliva is $0.1 \mathrm{ml} / \mathrm{min}$ and in stimulated saliva $0.7 \mathrm{ml} / \mathrm{min}^{23}$

HISTOPATHOLOGY

Minor salivary gland biopsies were performed by the procedure suggested by Daniels. ${ }^{64}$ After local anaesthesia, a $1.5 \mathrm{~cm}$ incision was made parallel to the vermilion border in the middle of the lower lip, between the midline and the corner of the mouth. Between five and 10 lobes of labial glands were obtained by blunt dissection. After removal, the mucosa was reapposed by using two to three interrupted sutures.

All glands were embedded in paraffin along the same plane, to provide midplane sections. Sections $5 \mu \mathrm{m}$ thick were stained with haematoxylin and eosin and evaluated under the microscope at $4 \times$ magnification, using a graticule to measure the number of foci per $\mathrm{mm}^{2}$. The focus score was defined as the number of agglomerations of at least 50 mononuclear cells per $4 \mathrm{~mm}^{2}$ of glandular tissue. Lymphoplasmacytic foci occurred adjacent to normal appearing acini. Focal sialadenitis was defined as focus score $\geqslant 1 .{ }^{21}$ If agglomerations of at least 50 mononuclear cells were observed, but there were less than one per $4 \mathrm{~mm}^{2}$ of glandular tissue, the focus score is expressed as $<1$. The histopathology and ranking procedures were performed blind by one investigator $(\mathrm{J} \mathrm{H} \mathrm{H})$, who was not aware of the diagnosis or symptoms of the patients.

\section{LABORATORY TESTS}

In addition to routine haematology and inflammatory variables, the laboratory tests included: rheumatoid factor (RF) measured by laser nephelometry; complement factors 3 (C3) and 4 (C4) measured by laser nephelometry; and ANA measured by using Hep-2 cells. Antibodies to extractable nuclear antigens (ENA), including specific antibodies to ribonuclear protein
(RNP), SSA (SSA), SSB (SSB), and Smith antigen $(\mathrm{Sm})$ were analysed by counterimmunoelectrophoresis. Sera were considered positive if the undiluted sample gave a positive precipitation line for the single antigen. RF was positive when it was $\geqslant 14 \mathrm{IU} / \mathrm{ml}$. ANA was positive when the titre was $\geqslant 1 / 160$. C3 was decreased when $\leqslant 0.70 \mathrm{~g} / 1$, and $\mathrm{C} 4$ was decreased when $\leqslant 0.11$ $\mathrm{g} / \mathrm{l}$. At the time of clinical research, an additional blood sample was collected, and sera were stored at $-20^{\circ} \mathrm{C}$ until analysed for antibodies to hepatitis $\mathrm{C}$ virus (HCV). Serum samples of 78 patients were available for the measurement of HCV antibodies, which was performed with a commercial enzyme immunoassay (ORTHO HCV 3.0 ELISA Test System SA Ve; Ortho Diagnostic Systems GmbH, Neckargemund, Germany) according to the manufacturer's instructions.

\section{STATISTICAL METHODS}

Differences in the prevalence rates were examined using $\chi^{2}$ test, likehood ratios, and Fisher's exact test. Significance of the differences in focus score values between the patient groups was estimated with the Kruskal-Wallis one way analysis of variance by ranks and Dunn's multiple comparison test. A post hoc test was applied when differences between individual patient groups were being sought. Correlations were analysed using the Spearman rank correlation test. Odds ratios (OR) for the presence of focal sialadenitis and their $95 \%$ confidence intervals $(95 \%$ CI) for different patient groups were analysed with a logistic regression model (NCSS 6.0 Statistical software). Two tailed p values of 0.05 or below were considered statistically significant.

\section{Results}

CLINICAL FINDINGS

Decreased salivary secretion (either unstimulated or stimulated) was most often observed in

Table 3 Patients on medication that decreased secretion of saliva or tears

\begin{tabular}{lllllll}
\hline $\begin{array}{l}\text { Age } \\
\text { (years) }\end{array}$ & $\begin{array}{l}\text { Sex } \\
(M / F)\end{array}$ & Disease & $\begin{array}{l}\text { Focal } \\
\text { sialadenitis }\end{array}$ & Medication & $\begin{array}{l}\text { Positive Schirmer's } \\
\text { test }\end{array}$ & $\begin{array}{l}\text { Decreased salivary } \\
\text { secretion }\end{array}$ \\
\hline 51 & F & RA & + & Carbamazepine & + & - \\
63 & F & RA & + & Chlorothiazide, amiloride & + & - \\
52 & F & RA & + & Chlorothiazide, amiloride & + & + \\
47 & F & RA & + & Amitriptyline & + & - \\
71 & F & RA & + & Chlorothiazide, amiloride & + & + \\
67 & F & MCTD & + & Amitriptyline & + & - \\
43 & F & SpA & + & Hydrochlorothiazide, amiloride & + & + \\
54 & M & AS & - & Amitriptyline, flupentixol & + & +
\end{tabular}

RA = Rheumatoid arthritis; MCTD = mixed connective tissue disease; AS = ankylosing spondylitis; SpA, spondyloarthropathy. 
patients with MCTD and least often in patients with $\operatorname{SpA}\left(\chi^{2}\right.$ test, $\mathrm{p}<0.001$; table 2$)$. Decreased tear secretion occurred most often in patients with MCTD and least often in patients with SpA ( $\chi^{2}$ test, $p=0.021$; table 2$)$. Eight of the 85 patients $(9 \%)$ currently used medication that decreased either salivary or tear secretion ${ }^{25}$ (table 3). Three had decreased salivary secretion, and all had decreased tear secretion. None of the subjects experienced major adverse effects from the labial salivary gland biopsy. One patient had a large haematoma, one experienced transiently decreased sensation in a small area in the lower lip, and, in another, there was excessive scar formation. One biopsy sample (patient with MCTD) was not representative and was therefore excluded from further analysis.

HISTOLOGICAL EXAMINATION

Focal sialadenitis was observed in $68 \%(57 / 84)$ of all patients. It affected $80 \%(20 / 25)$ of those with RA, 94\% (17/18) of those with MCTD, $58 \%(11 / 19)$ of those with AS, and 41\% (9/22) of those with $\mathrm{SpA}\left(\chi^{2}\right.$ test, $\mathrm{p}=0.0013$; table 2$)$. The median focus scores differed significantly among the study groups, being highest (4.1) in the MCTD group and lowest $(<1)$ in the SpA group (Kruskall-Wallis, $\mathrm{p}<0.0001$; fig 1 ).

ASSOCIATION BETWEEN FOCAL SIALADENITIS AND CLINICAL FINDINGS

Patients with focal sialadenitis more often had both decreased salivary secretion $(30 \% v 4 \%$; $\chi^{2}$ test, $\left.\mathrm{p}=0.0074\right)$ and decreased tear secretion $\left(58 \%\right.$ v $35 \% ; \chi^{2}$ test, $\left.\mathrm{p}=0.048\right)$ than patients without it. Focus scores correlated negatively with the amount of both unstimulated and stimulated saliva secretion (Spearman rank correlation test, $r_{\mathrm{s}}=-0.46,95 \% \mathrm{CI}-0.27$ to -0.61 ; and $r_{\mathrm{s}}=-0.51,95 \%$ CI -0.33 to -0.65 respectively). Focal sialadenitis tended to occur

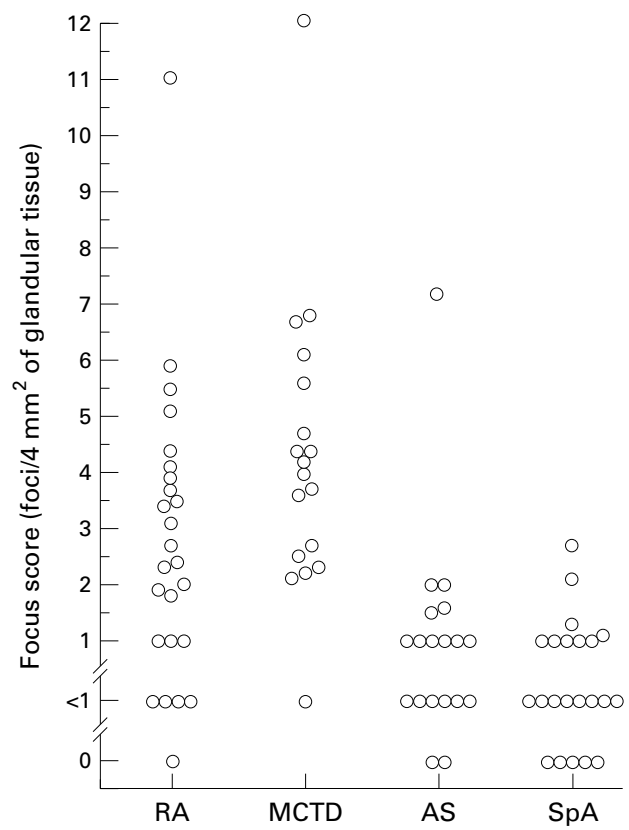

Figure 1 Focus scores in the study groups. $R A=$ rheumatoid arthritis; $M C T D=$ mixed connective tissue disease; $A S=$ ankylosing spondylitis; $S p A=$ spondyloarthropathy.
Table 4 Multiple logistic regression: odds ratios (OR) and confidence intervals (95\% CI) for focal sialadenitis

\begin{tabular}{llll}
\hline & \multicolumn{2}{l}{ Focal sialoadenitis } & \\
\cline { 2 - 3 } Characteristic & OR & $95 \%$ CI & p Value \\
\hline Age (years) & & & \\
$\quad$ Below 35 & 1 & & \\
35-45 & 2.12 & 0.52 to 8.70 & 0.30 \\
$\quad$ Over 45 & 12.17 & 2.36 to 62.69 & 0.0028 \\
Sex & & & \\
$\quad$ Female & 1 & & \\
$\quad$ Male & 0.57 & 0.14 to 2.38 & 0.44 \\
Rheumatoid factor & & & \\
$\quad$ Negative & 1 & & \\
$\quad$ Positive & 3.02 & 0.69 to 13.26 & 0.14 \\
Patient group & & & \\
$\quad$ SpA & 1 & & 0.48 \\
AS & 1.66 & 0.41 to 6.66 & 0.54 \\
RA & 1.74 & 0.30 to 10.06 & 0.049 \\
MCTD & 11.91 & 1.01 to 141.0 & 0.049 \\
\hline
\end{tabular}

RA = Rheumatoid arthritis MCTD = mixed connective tissue disease; $\mathrm{AS}=$ ankylosing spondylitis; $\mathrm{SpA}=$ spondyloarthropathy.

more often in women (41/55) than in men (16/ 29) ( $\chi^{2}$ test, $\left.p=0.071\right)$. In the multiple logistic regression model, increasing age and the MCTD group were independent risk factors for focal sialadenitis (table 4). No associations were observed between focal sialadenitis and disease duration or the use of corticosteroids or sulfasalazine (data not shown).

ASSOCIATION BETWEEN FOCAL SIALADENITIS AND LABORATORY VARIABLES

Patients with RF had focal sialadenitis significantly more often than patients without it $\left(\chi^{2}\right.$ test, $\mathrm{p}=0.002)$. Patients with focal sialadenitis had higher RF titres than those without it (Mann-Whitney, $\mathrm{p}<0.001$ ). Similarly, patients with positive ANA, SSA, or SSB had sialadenitis more often than patients without these antibodies ( $\chi^{2}$ test, $\mathrm{p}=0.0041,0.013$, and 0.077 respectively). No associations were observed between focal sialadenitis and low complement levels or the presence of RNP or Sm antibodies. HCV antibodies were negative in all the patients tested.

\section{SERONEGATIVE ARTHRITIS}

The subgroup of patients with AS or $\mathrm{SpA}$ was further analysed for risk factors for sialadenitis. The presence of focal sialadenitis was not associated with decreased salivary or tear secretion, the clinical type of disease (axial or peripheral arthritis), age, the use of medication (corticosteroids or sulfasalazine), disease duration, or the presence of ANA, ENA, SSA, SSB, RNP, Sm antibodies, positive RF, or low complement levels (data not shown).

\section{Discussion}

Focal sialadenitis was common in patients with various rheumatic diseases, being most common in those with MCTD, but also surprisingly common in those with AS or SpA. Focal sialadenitis was significantly associated with decreased secretion of saliva and tears. Significant associations were observed between focal sialadenitis and RF and its titre: ANA, and SSA and SSB antibodies. This observation was confined to patients with RA or MCTD. Increasing age and MCTD were independent risk factors for focal sialadenitis. No associations were 
observed between focal sialadenitis and disease duration or the use of corticosteroids or sulfasalazine.

\section{VALIDITY OF THE DATA}

The patients were chosen randomly. Salivary gland biopsy specimens of the lower lip were taken in a standard way. All of the specimens were representative except one, which was excluded. All patients were studied at the same time of day, and all of the tests were performed by one person with the same materials. It is possible that medication may have influenced the results on salivary or tear secretion, but this was carefully recorded. The use of sulfasalazine and corticosteroids had no effect on the occurrence of focal sialadenitis within each of the study groups.

The biopsy procedure described here for labial salivary gland is safe and effective if it is performed through clinically normal mucosa, if the specimen contains enough separate glands for interpretation, and if the histopathological examination includes determination of a focus score ${ }^{26}$ Focal sialadenitis in an adequate labial salivary gland specimen and is said to have good specificity and sensitivity for Sjögren's syndrome when the focus score is at least $1 .^{21}$ However, patients with Sjögren's syndrome can have a normal focus score with advanced disease ${ }^{27}$ or focal sialadenitis with normal salivary flow, ${ }^{27}$ indicating low specificity and sensitivity of the histological procedure in the diagnosis of Sjögren's syndrome.

COMPARISON WITH PREVIOUS DATA

Our results confirm previous findings on the high prevalence of focal sialadenitis and decreased salivary excretion in patients with MCTD. ${ }^{10}{ }^{28}$ Konttinen et $a l^{10}$ observed focal sialadenitis in nine and decreased salivary excretion in seven of ten patients with MCTD. These are comparable to the $94 \%$ and $61 \%$ prevalence rates respectively observed in our 18 patients with MCTD. In the present study, $80 \%$ of the patients with RA had focal sialadenitis, and $40 \%$ had sialadenitis combined with decreased salivary or tear secretion. These values are higher than those of Andonopoulos et al, ${ }^{1}$ who found focal sialadenitis in $31 \%$ and sialadenitis combined with clinical manifestations of Sjögren's syndrome in $24 \%$ of patients with RA. The difference can be explained by the scoring systems. Andonopoulos et $a l^{1}$ used Tarpley's classification ${ }^{29}$ from 1974, which accepts a higher number of inflammatory cell aggregates as pathological compared with the presently widely used scoring system applied by us. In agreement with previous work, ${ }^{11028}$ the focus scores in our patients with focal sialadenitis in association with MCTD or RA were distinctly abnormal. This contrasts with the small increase in the scores in patients with AS or SpA. Thus, although abnormal scores occurred in all the patient groups, patients with MCTD or RA differed distinctly from those with AS or SpA.

In the normal population, both tear secretion and salivary secretion are physiologically reduced in the elderly. ${ }^{21}$ Vitali et $a l^{21}$ found that the presence of inflammatory foci in lip biopsy specimens of patients without Sjögren's syndrome did not correlate with age, whereas Syrjänen ${ }^{30}$ observed that foci of inflammatory cells increased with age, as well as with acinar atrophy, ductal dilatation, and degree of fibrosis, among 78 healthy people. Disease duration did not correlate with focal sialadenitis in the present study, which is in accordance with the findings of Gerli et al. ${ }^{31}$

In patients with RA, the presence of ANA was observed in $44 \%$, a value comparable to that in the literature, ${ }^{32}$ while SSA/SSB antibodies were not present in RA. SSA/SSB antibodies are most common in patients with primary Sjögren's syndrome and systemic lupus erythematosus, ${ }^{33} 34$ but occur less often in patients with RA. ${ }^{35}$ In accordance with previous reports, ${ }^{36}$ we observed SSA/SSB antibodies in 58\% of the patients with MCTD. We used immunodiffusion to measure these antibodies. Immunodiffusion is less sensitive than enzyme linked immunosorbent assay (ELISA) for detecting SSA and SSB antibodies. ${ }^{34}$ Immunodiffusion detected these antibodies only in $0-2 \%$ of patients with RA, whereas the prevalence was $22-28 \%$ when measured by ELISA. ${ }^{38}$ The antibody levels have been shown to change in association with changes in the disease activity of patients with Sjögren's syndrome and systemic lupus erythematosus. ${ }^{39}$ The absence of SSA and SSB antibodies is further evidence for poor agreement between histology and autoantibodies, as discussed previously. ${ }^{33}$

In accordance with the findings of Saito et $a l,^{40}$ we observed an association between the presence of RF, ANA, SSA, or SSB and focal sialadenitis in biopsy samples of labial salivary gland. Patients with focal sialadenitis also had higher titres of RF than patients without sialadenitis. Shah et $a l^{41}$ and Gerli et $a l^{11}$ also found significant associations between focal sialadenitis in biopsy specimens of labial salivary gland and the presence of ANA, SSA, and SSB antibodies. An autoimmune focal sialadenitis, as confirmed by high focus scores in biopsy specimens of labial salivary gland in the present study, seems to be the most likely reason for decreased salivary secretion in patients with MCTD or RA.

A few studies have investigated the occurrence of focal sialadenitis in patients with AS or SpA. ${ }^{14}{ }^{152}$ In the present study, $58 \%$ of the patients with AS and $41 \%$ of those with SpA had focal sialadenitis. Whaley et $a l^{14}$ observed a distinct (grade III) focal sialadenitis in two of 12 patients with AS, neither of whom had decreased salivary or tear secretion. Brandt et $a l^{13}$ also found a definite focal sialadenitis (focus scores 2-13) in seven (7\%) of 105 patients with SpA or AS. However, Brandt et $a l^{13}$ collected samples only from patients who had a combination of both symptoms of dry mouth and/or eyes and positive ANA. The difference in prevalence of focal sialadenitis between our study and those of Whaley et $a l^{14}$ and Brandt et $a l^{13}$ can be explained by the different criteria for the definition of abnormal focus score. We accepted all patients with the focus score of $\geqslant 1$, as suggested by the present 
criteria. ${ }^{21}$ Despite the high occurrence of focal sialadenitis in the SpA group, none showed decreased salivary secretion, and the median focus score was quite low, suggesting that the sialadenitis was mild in this group. However, $23 \%$ of the patients with SpA had decreased tear secretion. The moderately increased focus scores observed in AS and SpA may be an indicator of mild sialadenitis. They can also be interpreted as reflecting poor specificity of focus scores, because of the low association with clinical findings. ${ }^{43}$ On the other hand, the focus score may be increased before the development of oral symptoms, ${ }^{44}$ indicating a need for follow up of the patients with abnormal focus score in the present study.

In conclusion, focal sialadenitis affects a high proportion of patients with MCTD, RA, AS, or $\mathrm{SpA}$. Its occurrence is significantly associated with RF, as well as with ANA, SSA and SSB antibodies. The association is most evident in RA and in MCTD. Because of the common problems in all the patient groups, the patients should be screened for ocular and oral symptoms, and, if symptomatic, should be referred for specialist care.

We are grateful to Professor Jukka Meurman, MD, DDS, and Dr Pekka Laine, DDS, for their valuable help in preparing the manuscript. We also thank Mrs Marjatta Kivekäs from the Department of Oral Pathology for preparing the histological slides. The work was supported by Helsinki University Central Hospital Research Funds.

1 Andonopoulos AP, Drosos AA, Skopouli FN, Skopouli FN, Acritidis NC, Moutsopoulos HM. Secondary Sjögren's syndrome in rheumatoid arthritis. J Rheumatol 1987;1:1098-103.

2 Kassan SS, Talal N. Sjögren's syndrome with systemic lupus erythematosus/mixed connective tissue disease. In: Talal N, Moutsopoulos HM, Kassan SS, eds. Sjögren's syndrome. Clinical and immunological aspects. Berlin: Springer Verlag. 1987:177-81.

3 Tsianos EV, Hoofnagle JH, Fox PC, Alspaugh M, Jones EA, Schafer DF, et al. Sjögren's syndrome in patients with primary biliary cirrhosis. Hepatology 1990;11:730-4.

4 Fox RI, Robinson CA, Curd JG, Kozin F, Howell FV. Sjögren's syndrome. Proposed criteria for classification. Sjögren's syndrome. Proposed criter
Arthritis Rheum 1986;29:577-85.

5 Vitali C, Bombardieri S, Moutsopoulos HM, Coll J, Gerli R, Hatron PY, et al. Assessment of the European classification criteria for Sjögren's syndrome in a series of clinically criteria for Sjögren's syndrome in a series of clinically
defined cases: results of a prospective multicentre study. defined cases: results of a prospecti

6 Daniels TE. Labial salivary gland biopsy in Sjögren's syndrome. Assessment as a diagnostic criterion in 362 suspected cases. Arthritis Rheum 1984;27:147-56.

7 Schiodt M, Thorn J. Criteria for the salivary component of Sjögren's syndrome. A review. Clin Exp Rheumato 1989;7:119-122.

8 Shah F, Rapini RP, Arnett FC, Warner NB, Smith CA Association of labial salivary gland histopathology with clinical and serologic features of connective tissue diseases. Arthritis Rheum 1990;33:1682-7.

9 Cleary KR, Batsakis JG. Biopsy of lip and Sögren's syndrome. Ann Otol Rhinol Laryngol 1990;99:323-5.

10 Konttinen YT, Tuominen TS, Piirainen HI, Könönen MH, Wolf JE, Hietanen JH, et al. Signs and symptoms in the masticatory system in ten patients with mixed connective masticatory system in ten patients with mixed connec

11 Syrjänen SM, Syrjänen KJ. Inflammatory cell infiltrate in labial salivary glands of patients with rheumatoid arthritis with special emphasis on tissue mast cells. Scand J Dent Res 1984;92:557-63.

12 Davies JD, Berry H, Bacon PA, Issa MA, Schofield JJ. Labial sialadenitis in Sjögren's syndrome and in rheumatoid arthritis. J Pathol 1973;109:307-14.

13 Brandt J, Rudwaleit M, Eggens U, Mertz A, Distler A, Sieper $\mathrm{J}$, et al. Increased frequency of Sjögren's syndrome in patients with spondyloarthropathy. J Rheumatol 1998;25:718-24.

14 Whaley K, Chisholm DM, Williamson J, Dick WC, Nuki G, Buchanan WW. Sjögren's syndrome in psoriatic arthritis, ankylosing spondylitis and Reiter's syndrome. Acta Rheum Scand 1971;17:105-14.

15 Clayman MD, Reinertsen JL. Ankylosing spondylitis with subsequent development of rheumatoid arthritis, Sjögren's syndrome, and rheumatoid vasculitis. Arthritis Rheum syndrome, and

16 Laversuch CJ, Collins DA, Charles PJ, Bourke BE. Sulfasalazine induced autoimmune abnormalities in patients with rheumatic disease. Br J Rheumatol 1995;34:435-9.
17 Arnett FC, Edworthy SM, Bloch DA, McShane DJ, Fries JF, Cooper NS, et al. The American Rheumatism Associa$\mathrm{JF}$, Cooper NS, et al. The American Rheumatism Associa-
tion 1987 revised criteria for the classification of rheumation 1987 revised criteria for the classification of
toid arthritis. Arthritis Rheum 1988;31:315-24.

18 Alarcon-Segovia D, Villarreal M: Classification and diagnostic criteria for mixed connective tissue diseases. In: Kasukava R, Sharp GC, eds. Mixed connective tissue diseases and anti-nuclear antibodies. Amsterdam: Elsevier, 1987:33-40.

19 Van der Linden S, Valkenburg HA, Cats A. Evaluation of diagnostic criteria for ankylosing spondylitis: a proposal for modification of

20 Dougados M, van der Linden S, Juhlin R, Huitfeldt B, Amor B, Calin A, et al. The European Spondyloarthropathy Study Group preliminary criteria for the classification of spondyloarthropathy. Arthritis Rheum 1991;34:1218-27. spondyloarthropathy. Arthritis Rheum 1991;34:1218-27.
Vitali C, Moutsopoulos HM, Bombardieri S. The European Community Study Group on diagnostic criteria for Sjögren's syndrome. Sensitivity and specificity of tests for ocular and oral involvement in Sjögren's syndrome. Ann Rheum Dis 1994;53:637-47.

22 Haldberg GP, Berens C. Standardized Schirmer tear test kit. Am J Ophthalmol 1961;51:840-2.

23 Heinze U, Birkhed D, Bijorn H. Secretion rate and buffer effect of resting and stimulated whole saliva as function of age and sex. Swed Dent J 1983;7:227-38.

24 Daniels TE. Salivary histopathology in diagnosis of Sjögren's syndrome. Scand J Rheumatol Suppl 1986;61:36-43.

25 Malmström M, Syrjänen S, Happonen R-P, HäyrinenImmonen R, Jungell P, Kuusilehto A, et al. Suun limakalvosairaudet [Diseases of oral mucosa] (in Finnish). In: Meurman JH, Murtomaa H, Le Bell Y, Autti H, Luukkanen M, eds. Therapia odontologica. Forssa: Academica, 1996;826-7.

26 Segerberg-Konttinen M, Konttinen YT, Bergroth V. Focus score in the diagnosis of Sjögren's syndrome. Scand J Rheumatol Supple 1986;61:47-51.

27 Katayama I, Nishiyama S, Nishioka K. Clinical and histological analysis of labial biopsy in Sjögren's syndrome. J Dermatol 1991;18:25-30.

28 Alarcon-Segovia D. Symptomatic Sjögren's syndrome in mixed connective tissue disease. J Rheumatol 1976;3:191-5.

29 Ramos-Niembro, Alarcon-Segovia. Development of sicca symptoms in systemic lupus erythematosus patients with existing subclinical abnormalities of lacrimal and/or salivary glands. Arthritis Rheum 1979;22:935-6.

30 Syrjänen S. Age-related changes in structure of labial minor salivary glands. Age Ageing 1984;13:159-65

31 Gerli R, Muscat C, Giansanti M, Danieli MG, Sciuto M, Gabrielli A, et al. Quantitative assessment of salivary gland inflammatory infiltration in primary Sjögren's syndrome: its relationship to different demographic clinical and serologic features of the disorder. Br J Rheumatol 1997;36:969-75.

32 Gordon MM, Prter DR, Capell HA. Does sulphasalazine cause drug induced systemic lupus erythematosus? No effect evident in a prospective randomised trial of 200 rheumatoid patients treated with sulphasalazine or auranofin over five years. Ann Rheum Dis 1999;58:288-90.

33 Montecucco C, Bestagno M, Cerino A, Caporali R, Carnevale R, Longhi M, et al. Anti-SSB/La antibodies in Sjögren's syndrome and related autoimmune diseases. Results of a quantitative immunoassay using a highly purified antigen. Clin Exp Rheumatol 1989;7:5-11.

34 Sturgess A. Recently characterised autoantibodies and their clinical significance. Aust N Z J Med 1992;22:279-89.

35 Froelich CJ, Wallman J, Skosey JL, Teodorescu M. Clinical value of an integrated ELISA system for the detection of 6

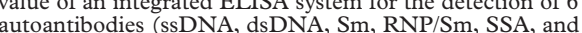
SSB). J Rheumatol 1990;17:192-200.

36 Pease CT, Shattles W, Charles PJ, Venables PJW, Maini RN. Clinical, serological, and HLA phenotype subsets in Sjögren's syndrome. Clin Exp Rheumatol 1989;7:185-90.

37 Piirainen IH, Kurki PT. Clinical and serological follow-up of patients with polyarthritis, Raynaud's phenomenon, and circulating RNP antibodies. Scand J Rheumatol 1990;19:51-6.

38 Maddison PJ, Skinner RP, Vlachoyiannopoulos P, Brennand DM, Hough D. Antibodies to nRNP, Sm, Ro(SSA) and La(SSB) detected by ELISA: their specificity and interrelations in connective tissue disease sera. Clin Exp Immunol 1985;62:337-345.

39 Wahren M, Tengner P, Tengner P, Gunnarsson I, Lundberg I, Hedfors E, et al. Ro/SS-A and La/SS-B antibody level variation in patients with Sjögren's syndrome and systemic lupus erythematosus. J Autoimmunol 1998;11:29-38.

40 Saito T, Fukuda H, Arisue M, Matsuda A, Shindoh M, Amemiya A, et al. Relationship between sialographic findings of parotid glands and histopathologic finding of labial glands in Sjögren's syndrome. Oral Surg Oral Med Oral Pathol 1991;72:675-80.

41 Shah F, Rapini RP, Arnett FC, Warner NB, Smith CA. Association of labial salivary gland histopathology with clinical and serologic features of connective tissue diseases. Arthritis Rheum 1990;33:1682-7.

42 Gusis SE, Villa NG, Maldonado Cocco JA, Barcelo HA, Scheines EJ, Catoggio LJ, et al. Sjögren's syndrome in seronegative spondyloarthropathies: an unusual finding. J Rheumatol 1994;21:771-2.

43 Lee M, Rutka JA, Slomovic AR, McComb J, Bailey DJ, Bookman AA. Establishing guidelines for the role of minor salivary gland biopsy in clinical practice for Sjögren's syndrome. J Rheumatol 1998;25:247-53.

44 Lindvall AM, Jonsson R. The salivary gland component of Sjögren's syndrome: an evaluation of diagnostic methods. Oral Surg Oral Med Oral Pathol 1986;62:32-4. 